\title{
Effect on human metabolic rate of skin temperature in an office occupant
}

\author{
Rosli Abu Bakar ${ }^{1, *}$, Norfadzilah Jusoh ${ }^{1}$, Ahmad Rasdan Ismail ${ }^{2}$, and Tanti Zanariah \\ Shamshir Ali ${ }^{1}$ \\ ${ }^{1}$ Faculty of Mechanical Engineering, Universiti Malaysia Pahang (UMP), 26600 Pekan Pahang, \\ Malaysia \\ ${ }^{2}$ Faculty of Creative Technology and Heritage, Universiti Malaysia Kelantan (UMK), Beg Berkunci \\ No. 01, 16300 Bachok, Kelantan, Malaysia
}

\begin{abstract}
The motivation of this study is to get a better understanding about the real thermal sensation of people in an office environment who undertakes moderate activities. The purpose of this study was to investigate occupant real thermal sensation at three tasks of activities and skin temperature to figure out its impact on thermal sensation in an office environment. All measurements were conducted in a climate chamber. In total, fifteen subjects were participated in three kinds of activities and skin temperatures, which is eleven locations were measured using thermocouple sensors. The results showed that the temperature is the one of the factors which affect metabolic rate. There is a strong linear relationship between these three tasks of activities and metabolic rate with the skin temperature. Furthermore, the results indicate that there was a greater increase thermal sensation when the metabolic rate 1.6. The conclusions of this study can provide some references to set a standard for air conditioning design and to set operating parameters of different functional architectures.
\end{abstract}

\section{Introduction}

Building environment has a great impact on people's health, comfort and productivity [1-3]. Thermal comfort studies are helpful to create a favorable indoor climate, maintain a productive thermal environment and keep reasonable energy consumption [4-6]. Most thermal comfort studies have focused on office building, classrooms or homes in which people usually sit or take low level activities. Actually, people may undertake various activities indoors such as those who work on assembling lines or those who exercise in building. With the increase of activity, the body heat production and thermal regulation process involved would be different from low activities [7]. Also, the thermal environment that makes people feel satisfied could not be similar.

Malaysia is a hot and humid tropical country that lies between $1^{\circ}$ and $7^{\circ}$ north and $100^{\circ}$ and $120^{\circ}$ east. Most locations have a relative humidity of $80-88 \%$ rising to nearly $90 \%$ in the highland areas and never fall below $60 \%$. The mean maximum daytime temperature

\footnotetext{
*Corresponding author: rosli@ump.edu.my
} 
recorded is $29-32{ }^{\circ} \mathrm{C}$ while the minimum temperature is $22-24{ }^{\circ} \mathrm{C}$ with a rainfall of 1000 $\mathrm{mm}$ per year $[8,9]$.

Based on the literature review, few thermal comfort studies have been conducted in Malaysia before the 1990s. According to the Energy Efficiency Guideline by the Ministry of Energy, Telecommunications and Posts (1989) and the Malaysia Standard MS 1525 [10], the proposed temperature for the air-conditioned nonresidential buildings is $23-26{ }^{\circ} \mathrm{C}$. These Figures are similar to the ASHRAE 55 [11] and ISO 7730 [12] standards. However, since 1990's with an increase of energy usage in the commercial sector, more research has been conducted in the area of thermal comfort to find appropriate means to provide comfortable indoor environments and to reduce energy consumption and costs. Studies have shown that an increase of $1.5{ }^{\circ} \mathrm{C}$ in indoor setting temperature give $15.8 \%$ energy saving $[13,14]$.

The purpose of this study was to investigate occupant real thermal sensation at three tasks of activities and skin temperature to figure out its impact on thermal sensation in an office environment.

\section{Experimental setup}

The experiment was carried out in a climate chamber $(\mathrm{L} \times \mathrm{W} \times \mathrm{H}=3.6 \mathrm{~m} \times 2.4 \mathrm{~m} \times$ $3.6 \mathrm{~m}$ ), which was placed inside an air conditioned room. Other than that, the air temperature inside the chamber could be controlled within $\pm 0.5{ }^{\circ} \mathrm{C}$. Fig. 1 showed the arrangement of the study. This diagram illustrated the environment of equipment was placed behind the subject.

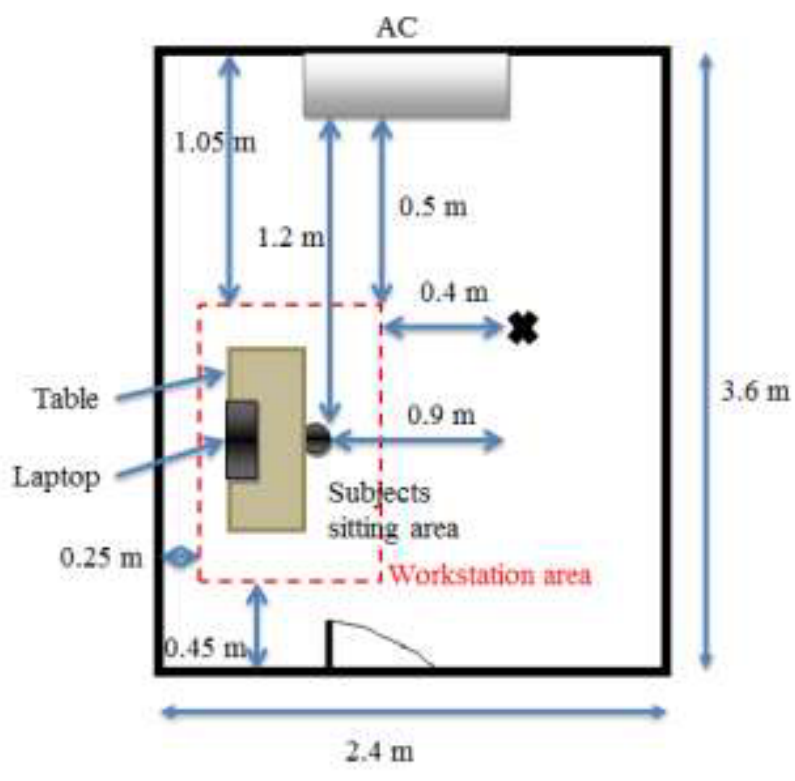

Fig. 1. The arrangement in environmental chamber.

\subsection{Design of experiment}

Thermal comfort tests with human subjects were conducted to test the thermal sensation of human for various thermal conditions. 15 volunteers (eight male and seven female) students 
were recruited in this study. The number of subjects in the study was agreed by Goldman [15]. He has 50 years' experience in the field of human thermal comfort and state that minimum subject for the study of human comfort is as many as six people.

All 15 subjects were using in this study to measure skin temperature while doing multitask in the chamber (represent an office room). There are three tasks the subjects must follow such as relaxing while sitting, typing or writing and printing paperwork as shown as in Table 1 .

Table 1. Types of the task with the metabolic rate.

\begin{tabular}{|c|c|c|}
\hline No. of Task & Types of the task & Metabolic rate (Met) \\
\hline 1 & Thinking & 1.0 \\
\hline 2 & Sitting while typing & 1.2 \\
\hline 3 & Printing & 1.6 \\
\hline
\end{tabular}

Existing thermoregulation models have selected three to fifteen body segments for skin temperature measurement to estimate mean skin temperature [16]. The most frequently used body locations for assessing skin temperature in the 16 existing thermoregulation models are the chest, thigh, anterior-calf, wrist, posterior upper arm, forehead, abdomen, hand, foot and scapula. The body areas are ordered by the selection frequency in the existing models alongside the sum of the weight factors assigned in each model's formula.

These body locations for skin temperature sensors are important for both control effectiveness and for practical system application of wearable sensors. In this study, 11 body locations were selected from those most frequently used in the existing models to measure skin temperatures, which are forehead, posterior upper arm, wrist, back of the hand, chest, belly, thigh, anterior calf, posterior calf, and instep of a foot. The sensing interval was $10 \mathrm{~min}$ for all the measurements. As the posterior-calf has a larger weight factor than the scapula, and is a more convenient sensor location, the researchers selected the posterior-calf as the 10 skin area for the experiment.

Thermocouple sensors used to measure skin temperature during the experimental chamber is running. Usually, the thermocouple sensors were held to the skin of different sites on the subjects (see Fig. 2) with porous medical tape to measure the local skin temperatures.

\subsection{Experimental procedure}

The steps and duration of experiment were shown in Table 2. The subjects entered the chamber and spent $10 \mathrm{~min}$ at the chamber prior to the test acclimatize with the room temperature [17-19]. All the three tasks of activities during which the subjects were exposed to multiple thermal conditions.

Table 2. Steps and duration of experiment.

\begin{tabular}{|c|c|c|}
\hline Step & Activity & Duration (min) \\
\hline 1 & Measured demographic of subjects & 30 \\
\hline 2 & Standby in a waiting room & 10 \\
\hline 3 & Start the measurement with Task 1 & $10 \times 5=50$ \\
\hline 4 & Break & 5 \\
\hline 5 & Task 2 & $10 \times 5=50$ \\
\hline 6 & Break & 5 \\
\hline 7 & Task 3 & $10 \times 5=50$ \\
\hline & Total & 200 \\
\hline
\end{tabular}




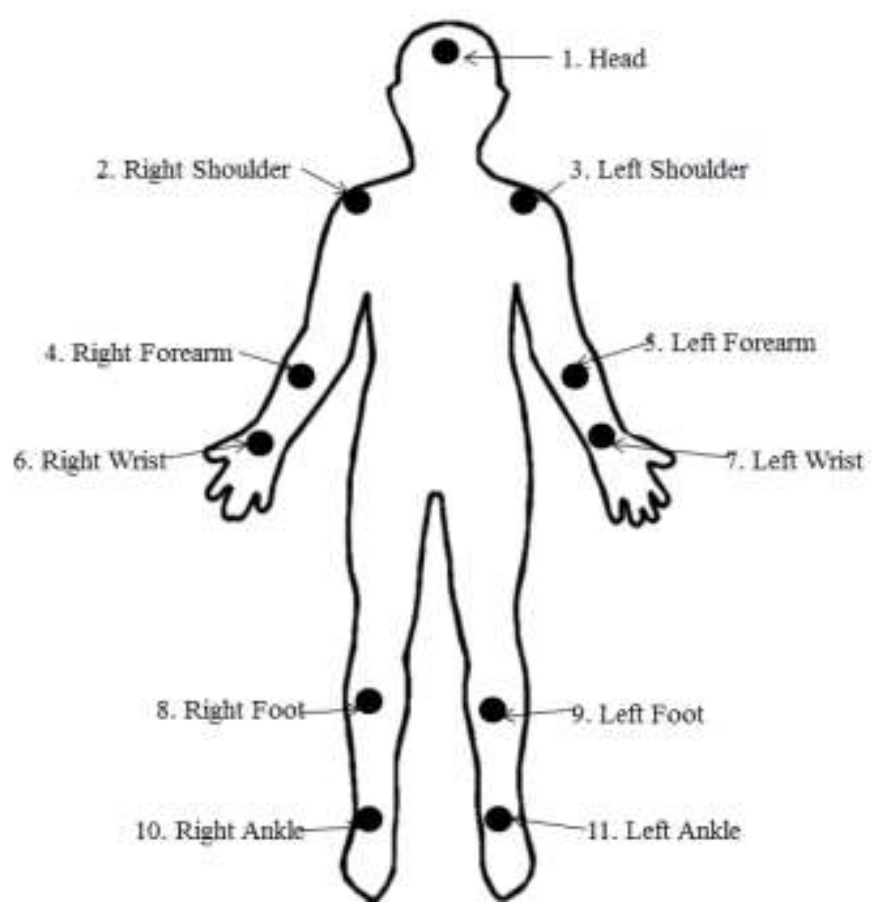

Fig. 2. Measurement points of skin temperature.

\section{Theoretical models}

This study is based on the thermal comfort of the human body. Therefore, it is necessary to understand what thermal comfort meaning and how to assess thermal comfort. Through many years' study on thermal comfort, Fanger [20] proposes conditions which is can satisfy thermal comfort; a) heat production and heat loss should satisfy the heat balance equation under the condition of steady state, $b$ ) skin temperature should be adapted to the thermal comfort level. Only satisfying these conditions at the same time can thermal comfort be realized. Thus, this paper based on these thermal comfort conditions to carry on this research.

\subsection{The body heat balance equation}

The suitable temperature is necessary to maintain the body's normal life people' activities. Thus, the body's heat production and heat dissipation should be in balanced. The body heat balance equation can be obtained [11] as Eq. (1):

$$
M-W=\left(C+R+E_{s k}\right)+\left(C_{r e s}+E_{r e s}\right)+S
$$

where, $M\left[\mathrm{~W} / \mathrm{m}^{2}\right]$ is metabolic rate, $W\left[\mathrm{~W} / \mathrm{m}^{2}\right]$ is mechanical work, $C\left[\mathrm{~W} / \mathrm{m}^{2}\right]$ is the convection heat loss of skin, $R\left[\mathrm{~W} / \mathrm{m}^{2}\right]$ is the radiation heat loss of skin, $E_{s k}\left[\mathrm{~W} / \mathrm{m}^{2}\right]$ the is skin evaporation heat loss, $C_{r e s}$ and $E_{\text {res }}\left[\mathrm{W} / \mathrm{m}^{2}\right]$ are sensible and latent respiratory heat loss, respectively, $S\left[\mathrm{~W} / \mathrm{m}^{2}\right]$ is heat storage of human body.

In general, $W$ is very low, for most kinds of activities, $W \approx 0$ [21]. $S$ is an important factor which affects the thermal comfort of dynamic environment [22]. However, the mainly consideration of this paper is steady state, so $S=0$. The detailed computational methods of variables in Eq. (1) can be expressed [11]: 
a) Convection heat loss, $C$ is the convection heat transfer between the body surface and the surrounding environment. When air temperature is higher than the surface skin temperature, the value of $C$ is positive, otherwise, the value of $C$ is negative. Convection heat loss can be obtained as follows:

$$
\begin{gathered}
C=f_{c l} h_{c}\left(t_{c l}-t_{a}\right) \\
f_{c l}=1 /\left(1+0.155 \times\left(h_{c}+h_{r}\right) \times I_{c l}\right) \\
t_{c l}=t_{s k}-0.155 \times I_{c l}\left(M-W-\left(C_{r e s}+E_{r e s}\right)-E_{s k}-S\right)
\end{gathered}
$$

where $f_{c l}$ is the clothing area coefficient; $h_{c}\left[\mathrm{~W} /\left(\mathrm{m}^{20} \mathrm{C}\right)\right]$ is a convective heat transfer coefficient, $h_{c}=8.3 V^{0.5} ; h_{r}\left[\mathrm{~W} /\left(\mathrm{m}^{20} \mathrm{C}\right)\right]$ is radiation heat transfer coefficient; $t_{c l}\left[{ }^{\circ} \mathrm{C}\right]$ is the clothing surface temperature; $t_{a}\left[{ }^{\circ} \mathrm{C}\right]$ is air temperature; $t_{s k}\left[{ }^{\circ} \mathrm{C}\right]$ is skin temperature; $I_{c l}\left[\left(\mathrm{~m}^{2} \mathrm{kPa}\right) / \mathrm{W}\right]$ is clothing insulation.

b) Radiation heat loss, $R$ is the radiation heat transfer between the body surface and the surrounding environment. When the surface skin temperature is higher than the mean radiant temperature, the value of $R$ is positive, otherwise, the value of $R$ is negative, which can be seen in Eq. (5):

$$
\begin{aligned}
& R=f_{c l} h_{r}\left(t_{c l}-t_{r}\right) \\
& h_{r}=f_{r a d} \varepsilon\left[\left(t_{c l}+273.15\right)^{2}+\left(t_{r}+273.15\right)^{2}\right] \times \\
& {\left[\left(t_{c l}+273.15\right)+\left(t_{r}+273.15\right)\right] \times 5.67 \times 10^{-8}}
\end{aligned}
$$

where $f_{\text {rad }}$ is the effective correction factor of human body surface, $f_{\text {rad }}=0.72$; $\varepsilon$ is the surface emissivity of the human body, $\varepsilon=0.97$.

c) Skin evaporation heat loss, $E_{s k}$ includes sweat evaporation heat loss and diffusion heat loss of moisture:

$$
\begin{gathered}
E_{s k}=\omega\left(p_{s k}-p_{a}\right) R_{e c l} h_{e} \\
R_{e c l}=1 /\left(1+0.143 \times h_{c} \times I_{c l}\right. \\
L R=h_{e} / h_{c}
\end{gathered}
$$

where $\omega$ is skin moisture index; $p_{s k}[\mathrm{kPa}]$ is a skin surface vapor pressure; $p_{a}[\mathrm{kPa}]$ is water vapor partial pressure of the surrounding air; $R_{e c l}$ is clothing moisture permeability coefficient; $L R=16.5$.

d) Respiratory heat loss includes sensible and latent respiratory heat loss, it can be obtained:

$$
C_{\text {res }}+E_{\text {res }}=0.0014 M\left(34-t_{a}\right)+0.0173 M\left(5.87-p_{a}\right)
$$

where $f_{c l}$ and $R_{c l}$ are determined by $I_{c} l$ and $h_{c} ; h_{c}$ and $p_{s k}$ are related to air velocity $(v)$ and $t_{s k}$, respectively; $t_{c l}$ is determined by $t_{s k}$ and $t_{a} ; p_{a}$ is determined by $t_{a}$ and $R H ; t_{s k}$ is related to $M$ and $W$. Thus, if $t_{a}, t_{r}, R H, v$ and $I_{c l}$ are known and the upper limit of $\omega$ determined, the biggest metabolic rate can be obtained under the condition of thermal comfort [23].

\section{Results and discussion}

\subsection{Skin temperature}

This section presents the relationship between the mean skin temperature and the thermal sensation which will also allow the prediction of thermal comfort. An analysis regarding 
the relationship between the mean skin temperature and the thermal sensation was conducted in order to determine the effect of metabolic rate on that relationship. The data were grouped based on the metabolic rate of the subjects.

Fig. 3 show effect of skin temperature on room temperature at different body segments. There are 11 body segments consists Head (1), Right Shoulder (2), Left Shoulder (3), Right Forearm (4), Left Forearm (5), Right Wrist (6), Left Wrist (7), Right Foot (8), Left Foot (9), Right Ankle (10) and Left Ankle (11) as illustrated in Fig. 2. Fig. 3 presented the highest body segment effect is left shoulder. This is because the left shoulder position is opposite with the door of the environmental chamber. All the body segment in left position is higher than right position. This also because, the right position faces the hanging wall of air conditioning. It also happens on the right forearm and right foot, both this body segments are placed on the table and on the floor. Furthermore, no barriers for temperature go through to these body segments.

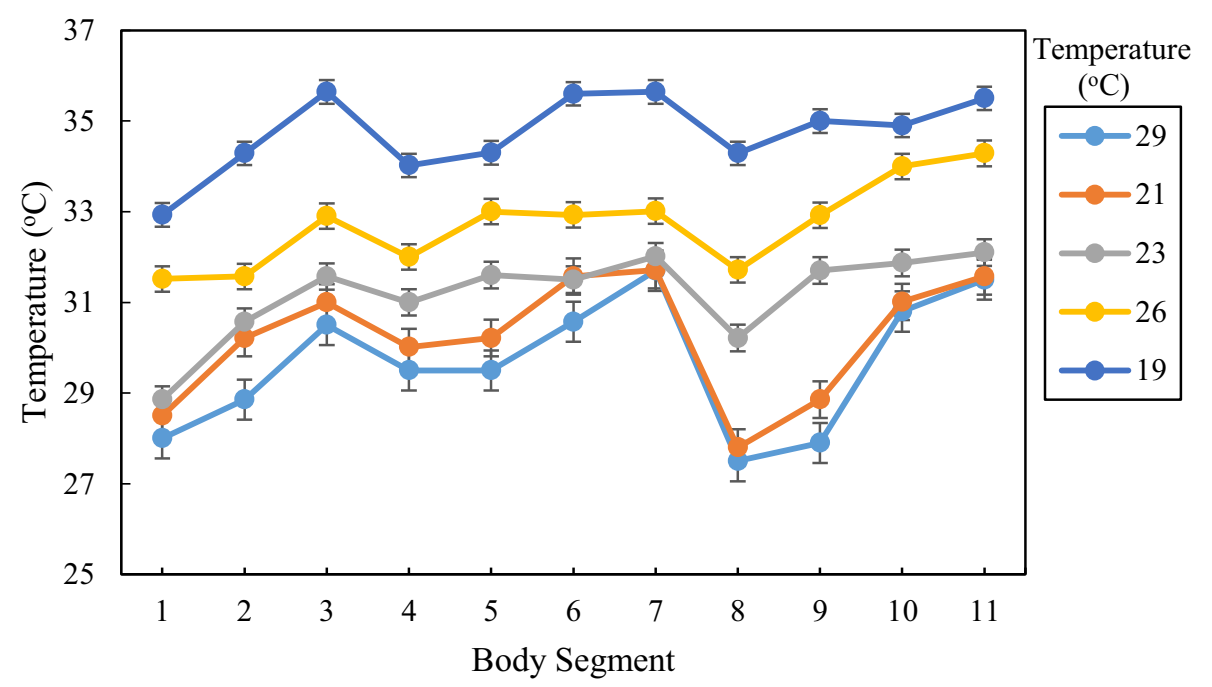

Fig. 3. Effect of skin temperature on room temperature at different body segments.

Fig. 4 shows that thermal sensation increased with the mean skin temperature in all three metabolic rate. For a given mean skin temperature, higher metabolic rate yielded a higher thermal sensation except around $34.89^{\circ} \mathrm{C}$ mean skin temperature $(p$-value $<0.001)$. The results of the regression analysis for thermal sensation (see Figure 3 ) show a strong linear dependency for skin temperature of human. The change in mean skin temperature yielded similar changes in thermal sensation for low and medium metabolic rate conditions. However, the change in thermal sensation during the high metabolic conditions was less than the other two conditions. It can be seen that a straight line fits the data well for 1.0, 1.2 and 1.6 Met $\left(R^{2}=0.7541, R^{2}=0.8679\right.$ and $\left.R^{2}=0.8467\right)$ respectively.

Under all conditions of activities, overall thermal sensation and skin temperature are correlated with each other closely. Skin temperature of $34.89{ }^{\circ} \mathrm{C}$ corresponds to thermal sensation of 0.79 , that is to say, the subjects felt uncomfortable when their whole body is $34.89{ }^{\circ} \mathrm{C}$ which are more rigid than the definition proposed by Gagge et al. [24] and Fanger [25]. 


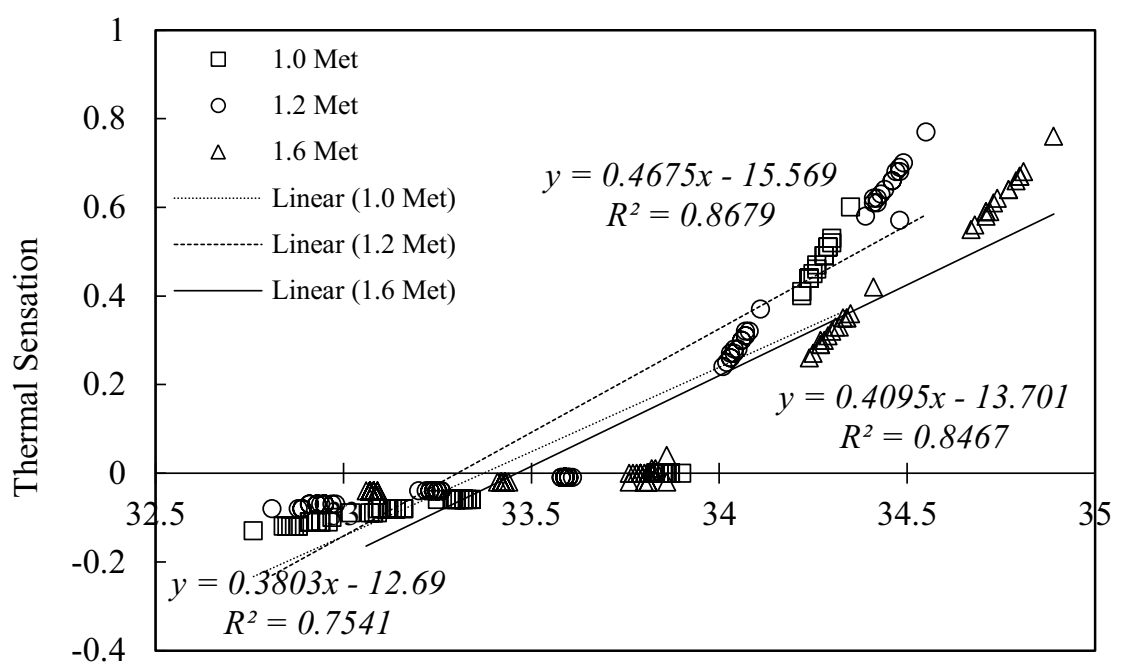

Skin Temperature $\left({ }^{\circ} \mathrm{C}\right)$

Fig. 4. The relationship between skin temperature and thermal sensation under three metabolic rate conditions.

\subsection{Heat balance and heat loss of the human body}

In this section, a heat balance analysis of the human body based on the specific test conditions was presented. The amount of heat stored inside the body was calculated through the increase in body temperature. The tympanic temperature measurements showed that the core body temperature is relatively stable throughout the experiment (see Table 3) and the difference between the measurements was statistically insignificant. Therefore, there was no heat storage in the body between the body temperature measurements and all the generated heat was dissipated to the environment through conduction, convection, radiation and evaporation.

Table 3. Body core temperature.

\begin{tabular}{|c|c|}
\hline Mean body core temperature $\left({ }^{\mathbf{}} \mathbf{C}\right)$ & Body core temperature Std. Dev. \\
\hline 36.85 & 0.029 \\
\hline
\end{tabular}

The evaporative heat losses for males and females are similar were calculated as $5.01 \mathrm{~W} / \mathrm{m}^{2}$ respectively as illustrated in Table 4.

Table 4. Evaporative heat loss in males and females.

\begin{tabular}{|l|c|c|c|c|}
\hline Gender & Average Met & $\begin{array}{c}\text { Average } \\
\text { surface area } \\
\left(\mathbf{m}^{\mathbf{2}}\right)\end{array}$ & $\begin{array}{c}\text { Duration of test } \\
\text { (hour) }\end{array}$ & $\begin{array}{c}\text { Evaporative heat loss } \\
\left(\mathbf{W} / \mathbf{m}^{\mathbf{2}}\right)\end{array}$ \\
\hline Male & 1.27 & 1.79 & 3.20 & 5.01 \\
\hline Female & 1.27 & 1.60 & 3.20 & 5.01 \\
\hline
\end{tabular}

An analysis was conducted to determine the relationship between the heat conduction through the body and the thermal comfort. The difference between the core temperature and skin temperature $\left(\Delta T_{c r}-T_{s k}\right)$ was normalized for body mass index (BMI) to take into account the insulation properties of the body. A significant correlation was detected 
between the $\Delta T_{c r}-T_{s k}$ and the thermal comfort at $\alpha=0.05$ (Pearson correlation: 0.58). Fig. 5 showed the relationship between these two variables. The correlation was also significant without BMI normalization, however, with a lower correlation coefficient (Pearson correlation: 0.21 ). This shows that thermal discomfort increases with the increased thermal strain on the body, which is the difference between the core body and the skin temperature. It can be seen that core body temperature a straight line fit data well $\left(R^{2}=0.58\right)$.

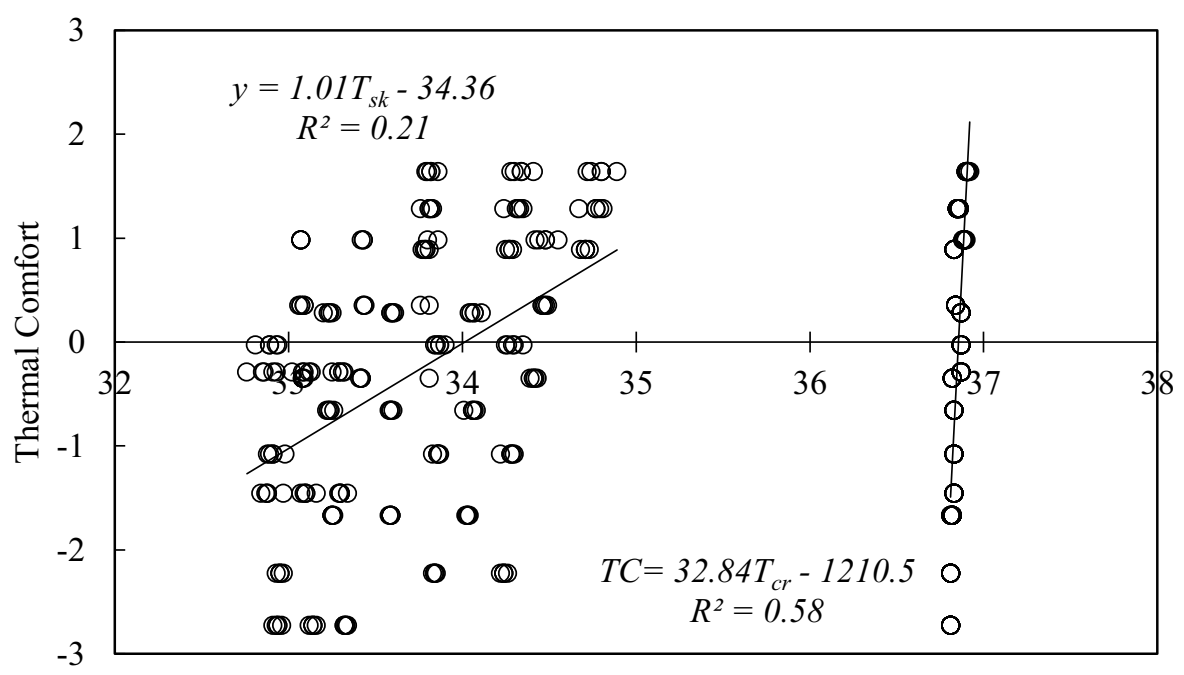

Difference between Core Body and Skin Temperature

Fig. 5. Correlation between thermal comfort and the difference between core body and skin temperature.

\section{Conclusions}

In this paper, the effect of the increased activity level of thermal sensation was investigated. Moreover, theoretical analysis and experiment were combined to study the metabolic rate on skin temperature in different thermal conditions. The conclusions of this paper can be drawn as follows:

a) Air temperature is the one factor which affects the metabolic rate in different thermal conditions.

b) The mathematical model was established according to experiment and the thermal sensation range of skin temperature to the metabolic rate.

The conclusions of this study can provide some references to set a standard for air conditioning design and to set operating parameters of different functional architectures. Besides that, this study can achieve the goals of thermal comfort and energy conservation to some extent.

The authors would like to thank the Higher Education Ministry and University Malaysia Pahang for the financial support and assistance from a research grant.

\section{References}

1. S. Tsushima, S.I. Tanabe, K. Utsumi, Workers' awareness and indoor environment quality in electricity-saving office, Building and Environment, 88(6), 10-19, (2015). 
2. R.J. de Dear, T. Akimoto, E.A. Arens, G. Brager, C. Candido, K.W. Cheong, B. Li, N. Nishihara, S.C. Sekhar, S. Tanabe, J. Toftum, H. Zhang, Y. Zhu, Progress in thermal comfort research over the last twenty years, Indoor Air, 23(6), 442-461, (2013).

3. L. Lan, P. Wargocki, Z. Lian, Quantitative measurement of productivity loss due to thermal discomfort, Energy and Building, 43(5), 1057-1062, (2011).

4. O. Seppanen, W.J. Fisk, Some quantitative relations between indoor environment quality and work performance or health, HVAC \& R Res, 12(4), 957-973, (2006).

5. M. Luo, R. de Dear, W. ji, C. Bin, B. Lin, Q. Quyang, Y. Zhu, The dynamics of thermal comfort expectations: The problem, challenge and implication, Building and Environment, 95, 322-329, (2016).

6. C. Dai, L. Lan, Z. Lian, Method for determination of optimal work environment in office buildings considering energy consumption and human performance, Energy and Building, 76(11), 278-283, (2014).

7. J.K. Vanos, J.S. Warland, T.J. Gillespie, N.A. Kenny, Review of the physiology of human thermal comfort while exercising in urban landscapes and implications for bioclimatic design, International Journal Biometeorol, 54(4), 319-334, (2010).

8. S.S. Ahmad, Thermal comfort and building performance of naturally ventilated apartment building in the Klang valley: A simulation study, Proceeding of the energy in buildings (sustainable symbiosis) seminar, 115-132, (2006).

9. A. Ahmad, Case study: Thermal comfort study demonstration low energy office (LEO), M.Sc Thesis, UKM, Malaysia, (2004).

10. Malaysia Standard, MS 1525 Code of practice on energy efficiency and use of renewable energy for non-residential buildings, Department of Standards Malaysia, (2001).

11. ASHRAE, ASHRAE handbook of fundamentals, comfort and health, American Society of Heating, Refrigerating and Air-Conditioning Engineers, Inc, Atlanta, USA, (2009).

12. ISO 7730, Moderate thermal environments: Determination of the PMV and PPD indices and specifications for thermal comfort, International Organization for Standardization, (1994).

13. S. Abdul Rahman, K.S. Kannan, A study of thermal comfort in naturally ventilated classrooms: Towards new indoor temperature standards, Proceeding of the Asia Pacific Conference on the Built Environment, Kuala Lumpur, Malaysia, (1997).

14. M. Zainal, C.C. Keong, Thermal comfort and energy conservation in factory buildings, Proceedings of the $7^{\text {th }}$ International Conference on Indoor Air Quality and Climate, 2, 601-606, (1996).

15. R.F. Goldman, Environmental ergonomics: Whence what wither, Proceeding of the $11^{\text {th }}$ International Conference on Environmental Ergonomics, 39-47, (2005).

16. Y. Yao, Z. Lian, W. Liu, Q. Shen, Experimental study on skin temperature and thermal comfort of the human body in a recumbent posture under uniform thermal environments. Indoor Built and Environment, 16(6), 505-518, (2007).

17. A.P. Gagge, J.A.J. Stolwijk, Y. Nishi, The prediction of thermal comfort when thermal equilibrium is maintained by sweating, ASHARE Transaction, 75, 108-125, (1969).

18. I.A. Strigo, F. Carli, C. Bushnell, Effect of ambient temperature on human pain and temperature perception, Anesthesiology, 92, 699-707, (2000).

19. S. Tanabe, N. Nishihara, M. Haneda, Indoor temperature, productivity and fatigue in office tasks, HVAC \& R. Research, 13, 623-633, (2007).

20. P.O. Fanger, Calculation of thermal comfort: Introduction of a basic comfort equation, ASHRAE Trans, 73(2), 1-20, (1967).

21. McIntyre, Indoor climate, Applied Science Publisher, London, (1980). 
22. L. Duanmu, L. Yu, H. Shu, Influence of human body heat storage and adaptation on thermal body, Refrig. Air Cond. Electr. Power Mach, 95(01), 30-33, (2004).

23. C. Yang, T. Yin, M. Fu, Study on the allowable fluctuation ranges of human metabolic rate and thermal environment parameters under the condition of thermal comfort, Building and Environment, 103, 155-164, (2016).

24. A.P. Gagge, J.A.J. Stolwijk, Y. Nishi, Comfort and thermal sensations and associated physiological responses at various ambient temperatures, Environmental Research, 1, 1-20, (1967).

25. P.O. Fanger, Thermal comfort: Analysis and applications in environmental engineering, Copenhagen, Denmark, Danish Technical Press, (1970). 